Ife Journal of Science vol. 20, no. 3 (2018)

\title{
PHOTOCATALYTIC DEGRADATION OF ALIZARIN RED DYE IN AQUEOUS SOLUTION USING TITANIA-NICKEL AND TITANIA-COBALT NANOCOMPOSITES
}

\author{
Odeyemi, O. T. ${ }^{\mathrm{a}}$, Owalude, S. O. ${ }^{\mathrm{b}}$ and Odebunmi, E. O.* ${ }^{\mathrm{b}}$ \\ ${ }^{a}$ Department of Science Laboratory Technology, Kwara State Polytechnic, Ilorin, Nigeria \\ ${ }^{b}$ Department of Chemistry, University of Ilorin, P.M.B. 1515, Ilorin, Nigeria \\ *Corresponding Author e-mail address: sowalude@gmail.com \\ (Received: 15th December, 2017; Accepted: 29th September, 2018)
}

\section{ABSTRACT}

\begin{abstract}
Titanium dioxide $\left(\mathrm{TiO}_{2}\right)$ was prepared by Sol-gel method which involved hydrolysis of Titanium trichloride $\left(\mathrm{TiCl}_{3}\right)$ with concentrated hydrochloric acid and oxidation by hydrogen peroxide. Doping of the $\mathrm{TiO}_{2}$ was effected at $10 \% \mathrm{Ni}_{-}-\mathrm{TiO}_{2}$ and $10 \% \mathrm{Co}^{-} \mathrm{TiO}_{2}$ using aqueous solutions of nickel nitrate and cobalt nitrate respectively. Characterization by X-ray Diffraction Crystallography (XRD) and Scanning Electron Microscopy (SEM) showed that the surface area and crystallinity of $\mathrm{TiO}_{2}$ increased through doping. The XRD and SEM data confirmed the observed increase in the photocatalytic activities of the doped versus the undoped $\mathrm{TiO}_{2}$ photocatalysts. Photocatalytic activities of both the doped and undoped $\mathrm{TiO}_{2}$ was investigated on the photodegradation of Alizarin red dye. With a constant dye concentration of $25 \mathrm{ppm}$ and temperature of $40^{\circ} \mathrm{C}$, it was observed that for all varying concentrations except $0.25 \mathrm{~g} / 1$ of catalyst at $240 \mathrm{mins}$, the percentage degradation was of the order $\mathrm{TiO}_{2}<\mathrm{Co}-\mathrm{TiO}_{2}<\mathrm{Ni}-\mathrm{TiO}_{2}$. At the $0.25 \mathrm{~g} / 1$ concentration of catalyst at 240 mins, the photocatalytic activities of the $\mathrm{Ni}-\mathrm{TiO}_{2}$ and $\mathrm{Co}-\mathrm{TiO}_{2}$ were observed respectively to be about 9 times and 12 times that of the $\mathrm{TiO}_{2}$.
\end{abstract}

Key Words: Titanium dioxide, titania-nickel, titania-cobalt,alizarin red and photocatalysts.

\section{INTRODUCTION}

Water pollution caused by indiscriminate discharge of wastes into water bodies render the water unfit for human or biological use (Mann et al., 2014). Among these contaminants, organic dyes generated from dye-producing or dyeconsuming industries are frequently discharged into the water bodies. Dyes generally have complex aromatic molecular structures making them stable and extremely resistant towards biological or chemical degradation processes (Tehrani-Bagha et al., 2010; Nguyen and Juang 2013). Dyes as major organic water pollutants are classified into different groups according to their chemical components termed "chromophore". Therefore, degradation of any dyes are better studied according to the chromophore rather than other classes (Hunger et al., 2004).

Alizarin red (1,2-dihydroxyanthraquinone) is a type of dye having anthraquinone chromophore. It can be obtained naturally from the root of madder and synthetically from anthracene and used to make other forms of the dye e.g. Turkey red, Alizarin blue and Alizarin orange (Bien et al. 2005). A basic characteristic is its slight solubility in water; therefore in ancient times, it was used as a histological stain. Alizarin red dye may result in potential risks of bioaccumulation, retardation in growth of aquatic organisms, adverse effect on photosynthesis by marine flora and cause threats to human health through the food chain transport (Hao et al., 2000; Tayade et al. 2007).

Degradation of organic dye pollutants can be carried out using conventional physical, chemical and biological methods (Ashfaq and Khatoon, 2014). Some of these methods are limited by their high cost, inability to remove soluble dyes and addition of chemicals (Poyatos et al., 2010). Advanced oxidation processes have been discovered to completely degrade dye molecules from waste water. Of all these processes, photocatalysis emerged as the most promising treatment method for various dyes on a laboratory scale (Kulkarni and Thakur, 2014). Photocatalysis is a method that uses light to generate active species on light-sensitive compounds (photocatalysts) to effect water purification. Some of these active species are hydroxyl radicals $(\mathrm{OH})$ which are generated in sufficient quantities to effect the degradation (Hao et al., 2000; Catrinescu et al., 2004; Eslami et al., 2007). 
Literature reports showed that the activities of photocatalysts had been increased through doping (Rauf and Ashraf, 2009). Photocatalyst's doping involves the introduction of two or more elements (metals or non-metals) into the structure of catalyst which then results in the insertion of energy levels between the conduction and valence bands of the catalyst (Barolo et al. 2012). The inserted energy levels provide sub-band gap irradiation from which electrons can be excited from dopant d-band to conduction band or from valence band to dopant d-band by lower energy photons than are required by the pure photocatalysts (Ibhadon and Fitzpatrick, 2013).

In this work, Alizarin red dye was photodegraded by synthesized $\mathrm{TiO}_{2}, \mathrm{Ni}-\mathrm{TiO}_{2}$ and $\mathrm{Co}-\mathrm{TiO}_{2}$ photocatalysts. These photocatalysts were characterized by various analytical techniques and their photocatalytic activities for the degradation of Alizarin red dye were compared.

\section{MATERIALS AND METHODS}

\section{Materials}

Reagents used were Titanium trichloride (Tianjin Damao Chemicals, China), concentrated hydrochloric acid (BDH Laboratory Poole, England), 95\% Ethanol (BDH Laboratory Poole, England), Ammonia solution and Hydrogen peroxide (Sigma-Aldrich). All reagents were of analytical grade and were used without further purification.

\section{Synthesis of doped and undoped $\mathrm{TiO}_{2}$}

The experimental method used was the Sol-gel method described by Molea and Propescu (2011) and Wang et al. (2015). Distilled water and 10\% $\mathrm{TiCl}_{3}$ containing $15 \% \mathrm{HCl}$ solution (50 $\mathrm{ml}$ each) were added together with $75 \mathrm{ml} 30 \% \mathrm{NH}_{3}$ solution in a $500 \mathrm{ml}$ flat-bottomed flask. The solution was continuously stirred after which it was refluxed for $24 \mathrm{~h}$ at $70^{\circ} \mathrm{C}$. The resultant solution was allowed to cool, thereafter $75 \mathrm{ml}$ of $\mathrm{H}_{2} \mathrm{O}_{2}$ was added. A yellow precipitate developed which was aged for 12 hours to form titaniumperoxo complex solution. The solution was then heated for 4 hours at $70^{\circ} \mathrm{C}$ to give a gel-like substance which was dissolved in water, autoclaved for 24 hours and then oven-dried for 1 hour at $70^{\circ} \mathrm{C}$. The dried product was calcined at $450^{\circ} \mathrm{C}$ for 1 hour and the titanium dioxide powder obtained was stored in air tight bottles.

The doped $\mathrm{TiO}_{2}$ catalysts were prepared at concentration of $10 \%$ each for the nickel and cobalt as dopants. To prepare $10 \% \mathrm{Ni}^{-} \mathrm{TiO}_{2}, 0.50 \mathrm{~g}$ of $\mathrm{Ni}\left(\mathrm{NO}_{3}\right)_{2}$ salt was added to $100 \mathrm{ml}$ of a mixture of distilled water and ethanol (3:1v/v) (Kumar et al., 2015) and $4.50 \mathrm{~g}$ of the $\mathrm{TiO}_{2}$ was added to the metal solution and stirred. The solution was then refluxed for 4 hours at $70^{\circ} \mathrm{C}$. The resulting solution was cooled and oven-dried at $70^{\circ} \mathrm{C}$ for 4 hoursand then calcined for 1 hour. The nickel-doped titanium dioxide powder was stored in an air tight bottle. The process was repeated for $10 \% \mathrm{Co}-\mathrm{TiO}_{2}$ using its corresponding nitrate salt.

\section{Characterization}

The synthesized photocatalysts were characterized using Scanning Electron Microscopy and X-ray Diffraction methods. The Scanning Electron Microscopy (SEM) was recorded on a Scanning Electron microscope (Aspex 3020) at an accelerating voltage of $16.0 \mathrm{kV}$ and the images were obtained at a magnification of 250x.The X-ray diffraction (XRD) patterns were recorded on a powder X-ray diffractometer (Bruker D8 Advance) using $\mathrm{Cu}-\mathrm{K} \alpha$ radiation. Diffraction patterns were recorded in the $2 \theta$ scale ranging from $10^{\circ}$ to $90^{\circ}$ at step interval of $0.034^{\circ}$.

\section{Photocatalytic activities}

A 25 ppm solution of Alizarin red (AR) dye was prepared using distilled water. The dye degradation began with varying concentrations of the photocatalysts ranging from $0.10 \mathrm{~g} / 1$ to 0.30 $\mathrm{g} / 1$ at a constant temperature of $40^{\circ} \mathrm{C}$. The solution was transferred to the reactor which was irradiated with a UV lamp. About $5 \mathrm{~cm}^{3}$ sample was withdrawn at regular time intervals of 30 mins up to a maximum of 240 mins. The Absorbance of each sample was measured at $340 \mathrm{~nm}$, the wavelength corresponding to maximum absorbance. The experiment was repeated for the doped photocatalysts. The absorbance of the dye solution at $40^{\circ} \mathrm{C}$ when no catalyst was present was also measured as blank, and the percentage degradation was calculated at each sampling time using the equation:

$$
\% \text { degradation }=\frac{A_{0}-A_{t}}{A_{0}} \times 100
$$


where $A_{o}$ and $A_{t}$ are the initial absorbance (blank absorbance) and absorbance after various intervals of time, $t$ respectively. The photocatalytic activities of the doped and undoped photocatalysts were thus measured and compared.

\section{RESULTS AND DISCUSSION}

The Scanning Electron Microscopy (SEM) was used to observe the morphological changes that occurred as a result of doping of the $\mathrm{TiO}_{2}$ photocatalysts by the nickel and cobalt metals. The SEM micrographs are presented in Fig. 1.It was observed that all the catalysts were similar in shape. However, the doped $\mathrm{TiO}_{2}$ had smaller particles than the undoped. $\mathrm{TiO}_{2}$ can be said to slightly fragment at the incorporation of the nickel and cobalt metals which led to increase in surface area of the doped catalysts. With increased surface area of the catalyst, increased degradation is expected on the part of the doped catalysts (Chanderia et al., 2017). The particle sizes of the $\mathrm{TiO}_{2}, \mathrm{Ni}-\mathrm{TiO}_{2}$ and $\mathrm{Co}-\mathrm{TiO}_{2}$ are $16.6 \mathrm{~mm}, 16.5 \mathrm{~mm}$ and $16.0 \mathrm{~mm}$ respectively.

The XRD patterns of all the catalysts are presented in Fig. 2. The XRD patterns of $\mathrm{Ni}-\mathrm{TiO}_{2}$ and $\mathrm{Co}-\mathrm{TiO}_{2}$ exhibited strong diffraction peaks at $25.2^{\circ}, 37.8^{\circ}, 48.1^{\circ}, 53.8^{\circ}$ and $62.6^{\circ}$ confirming anatase $\mathrm{TiO}_{2}$ while the XRD pattern of the undoped $\mathrm{TiO}_{2}$ exhibited strong diffraction peaks at $27.4^{\circ}, 36.1^{\circ}, 41.2^{\circ}, 54.3^{\circ}$ and $69.0^{\circ}$ confirming rutile $\mathrm{TiO}_{2}$ (Munusamy et al., 2013). It was observed that the peak intensity of diffraction pattern increased proportionally then decreased from undoped to the doped. Therefore, doping with both Nickel and Cobalt metals altered the crystal form of $\mathrm{TiO}_{2}$ from rutile to anatase phase. The results also showed that the crystal plane (110) for $\mathrm{TiO}_{2}$ appeared at $27.5^{\circ}$ while the crystal plane (101) for both $\mathrm{Ni}-\mathrm{TiO}_{2}$ and $\mathrm{Co}-\mathrm{TiO}_{2}$ appeared at $25.3^{\circ}$ which are all in agreement with literature reports and spectrum of the JCPDS (Joint Committee on Powder Diffraction Standards)(Li and Chen, 2011; Landmann et al., 2012). The crystallites sizes of all the photocatalysts were calculated using the Scherrer equation and were observed to be $0.9 \mathrm{~nm}, 1.41 \mathrm{~nm}$ and $1.41 \mathrm{~nm}$ respectively for the $\mathrm{TiO}_{2}, \mathrm{Ni}-\mathrm{TiO}_{2}$ and $\mathrm{Co}-\mathrm{TiO}_{2}$.
The photocatalytic activities of the samples were distinguished based on the catalyst loading. These are presented in Fig. 3 and summarized by the data presented in Table 1 . The amount of catalyst used for the dye degradation was effected in the range $0.10 \mathrm{~g} / \mathrm{l}-0.30 \mathrm{~g} / \mathrm{l}$. The $\%$ degradation of the undoped and doped $\mathrm{TiO}_{2}$ were observed to increase as the amount of catalyst increased up to $0.25 \mathrm{~g} / 1$. Literature report indicate that the surface area of catalyst available for degradation increased with increase in the amount of the catalyst leading to a rise in the rate of reaction is usually observed (Chanderia et al., 2017). The increase in the rate of dye degradation has also been attributed to the availability of more sites on the catalyst surface until an optimum level was reached (Munusamy et al., 2013). It was observed from Table 1 that the rate of dye degradation tends to decrease at high catalysts' loading. This decrease has been attributed to the agglomeration of catalyst particles at higher concentration than the optimum level (Munusamy et al. 2013). The decrease in \% degradation at high catalyst loading has also been attributed to the reduction in the penetration of light with increase in the amount of catalyst beyond the critical point (Mahadwad et al.2011).

Catalyst loading of $0.25 \mathrm{~g} / \mathrm{l}$ of undoped $\mathrm{TiO}_{2}$ presented about $20 \%$ degradation at 60 mins on stream. This $\%$ degradation decrease to about 6 times its initial \% degradation as the time increased to 240 mins. It shows that the maximum degradation achievable by the undoped catalyst was $20 \%$ at 60 mins. However, $0.25 \mathrm{~g} / 1$ of the doped $\mathrm{TiO}_{2}$ presented $21.6 \%$ in $\mathrm{Ni}-\mathrm{TiO}_{2}$ and $22.02 \%$ in $\mathrm{Co}^{-} \mathrm{TiO}_{2}$ at $60 \mathrm{mins}$ and increased respectively to about 1.4 times and 1.9 times their initial degradation at 240 mins. This implies that the doped forms increased the catalytic activities of the undoped form beyond its degradable efficiency with time. This is attributed to the ability of dopants to suppress the recombination of photo-induced electron-hole pairs thereby increasing the photocatalytic efficiency in the $\mathrm{TiO}_{2}$ (Zhang and Liu, 2008). In essence, it can be concluded that the photocatalytic activities of the $\mathrm{Ni}-\mathrm{TiO}_{2}$ and $\mathrm{Co}-\mathrm{TiO}_{2}$ were respectively about 9 times and 12 times that of the $\mathrm{TiO}_{2}$ in the present study 
It was also observed that $\mathrm{Ni}-\mathrm{TiO}_{2}$ showed a higher degradation of $35.51 \%$ at catalyst loading of 0.2 $\mathrm{g} / \mathrm{l}$ than its expected optimum concentration of $0.25 \mathrm{~g} / \mathrm{l}$. This may imply that doping with respect to nickel metal shifted the expected optimum concentration to a lower concentration of catalyst while an optimum degradation was maintained. Therefore, the $0.20 \mathrm{~g} / 1 \mathrm{Ni}-\mathrm{TiO}_{2}$ possess equal characteristics as $0.25 \mathrm{~g} / 1 \mathrm{Co}-\mathrm{TiO}_{2}$ and undoped $\mathrm{TiO}_{2}$.

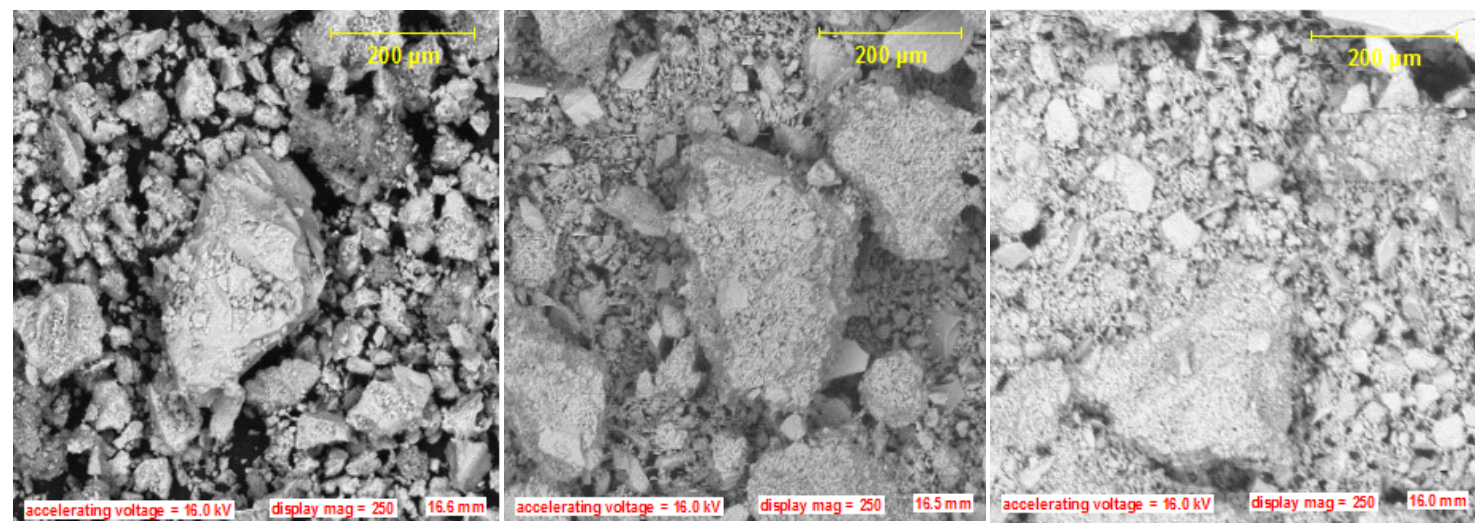

Fig. 1: SEM images of (a)undoped $\mathrm{TiO}_{2}$ (b) $\mathrm{Ni}-\mathrm{TiO}_{2}$, (c) $\mathrm{Co}-\mathrm{TiO}_{2}$

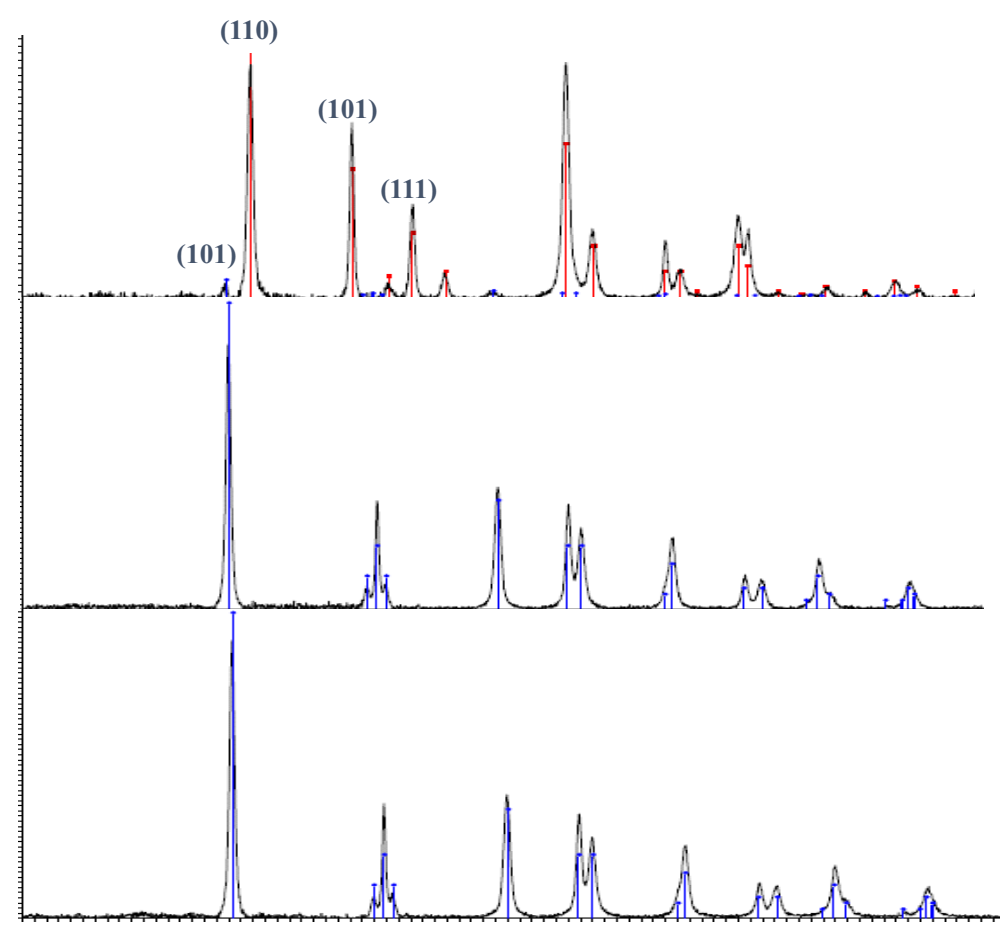

Fig. 2: XRD patterns of (a) undoped $\mathrm{TiO}_{2}$ (b) $\mathrm{Ni}--\mathrm{TiO}_{2}$ (c) $\mathrm{Co}-\mathrm{TiO}_{2}$
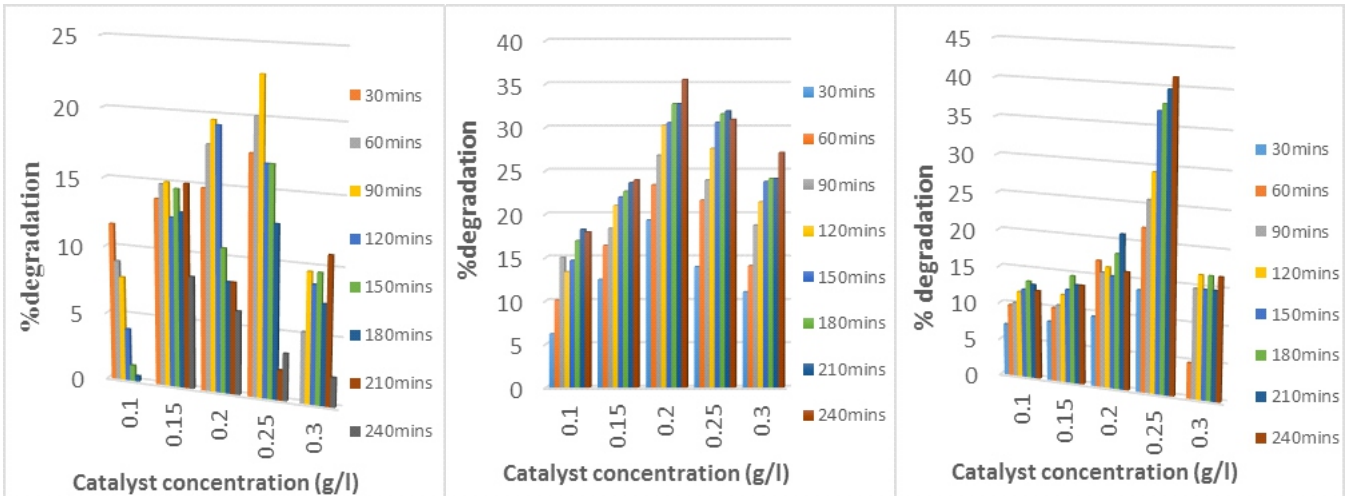

Fig. 3: Effect of catalyst concentration on the photocatalytic degradation of $25 \mathrm{ppm}$ Alizarin red dye at $40^{\circ} \mathrm{C}$ using (a) Undoped $\mathrm{TiO}_{2}$ (b) $\mathrm{Ni}-\mathrm{TiO}_{2}$ and (c) $\mathrm{Co}-\mathrm{TiO}_{2}$ 
Table 1: Summary of photocatalytic activities of $\mathrm{TiO}_{2}, \mathrm{Ni}-\mathrm{TiO}_{2}$ and $\mathrm{Co}-\mathrm{TiO}_{2}$

\begin{tabular}{|c|c|c|c|c|c|c|c|c|c|c|c|c|}
\hline \multirow{3}{*}{$\begin{array}{l}\text { [catalyst] } \\
(\mathrm{g} / \mathrm{l}) / \text { time } \\
\text { (mins) }\end{array}$} & \multicolumn{12}{|c|}{$\%$ degradation } \\
\hline & \multicolumn{4}{|c|}{$\mathrm{TiO}_{2}$} & \multicolumn{4}{|c|}{$10 \% \mathrm{Ni}-\mathrm{TiO}_{2}$} & \multicolumn{4}{|c|}{$10 \% \mathrm{Co}-\mathrm{TiO}_{2}$} \\
\hline & 60 & 120 & 180 & 240 & 60 & 120 & 180 & 240 & 60 & 120 & 180 & 240 \\
\hline 0.3 & 5.24 & 8.73 & 7.42 & 2.18 & 14.05 & 21.41 & 24.08 & 27.09 & 4.8 & 16.61 & 16.61 & 16.61 \\
\hline 0.25 & 20.06 & 16.88 & 12.74 & 3.5 & 21.6 & 27.58 & 31.56 & 30.9 & 22.02 & 29.28 & 37.92 & 41.28 \\
\hline 0.2 & 17.9 & 19.28 & 8.25 & 6.19 & 23.37 & 26.79 & 32.71 & 35.51 & 17.11 & 16.35 & 18.25 & 15.97 \\
\hline 0.15 & 14.83 & 12.5 & 12.92 & 8.33 & 16.39 & 20.98 & 22.62 & 23.93 & 10.49 & 11.97 & 14.67 & 13.51 \\
\hline 0.1 & 8.92 & 3.88 & 0.39 & - & 10.1 & 13.36 & 16.94 & 17.92 & 9.77 & 11.72 & 13.28 & 12.11 \\
\hline
\end{tabular}

\section{CONCLUSION}

$\mathrm{TiO}_{2}$ has been shown to be an effective catalyst for the degradation of Alizarin red dye. The photocatalytic degradation of the $\mathrm{TiO}_{2}$ was enhanced by doping. The $\%$ degradation of both the doped and undoped catalysts was observed to be influenced by the amount of catalyst at constant dye concentration and temperature.

\section{REFERENCES}

Ashfaq, A. and Khatoon, A. 2014. Waste Management of Textiles: A Solution to the Environmental Pollution. International Journal of Current Microbiology and Applied Sciences. 3(7):780-787.

Barolo, G., Livraghi, S., Chiesa, M., Paganini, M. C., Giamello, E. 2012. "Mechanism of the Photoactivity under visible light of $\mathrm{N}$ doped Titanium dioxide: Charge carriers migration in irradiated $\mathrm{N}-\mathrm{TiO}_{2}$ investigated by electron paramagnetic resonance. Journal of Physical Chemistry C, 116:20887-20894.

Bien, H.S, Stawitz, J. and Wunderlich K. 2005. Anthraquinone Dyes and Intermediates. Ullmann's Encyclopedia of Industrial Chemistry, Weinheim: Wile-VCH, p 355.

Catrinescu, C., Cha S. Y. and Yang, H. Y. 2004. Improvement of oxidative decomposition of aqueous phenol by microwave irradiation in $\mathrm{UV} / \mathrm{H}_{2} \mathrm{O}_{2}$ process and kinetic study. Water Research 38:2782-2790.

Chanderia, K., Kumar, S., Sharma, J., Ameta, R. and Punjabi, P.B. 2017. Degradation of sunset yellow FCF using copper-loaded bentonite and $\mathrm{H}_{2} \mathrm{O}_{2}$ as photo-Fenton-like reagent." Arabian Journal of Chemistry, 10: s205-s211.
Eslami, A., Nasseri, S., Yadollahi, B., Mesdaghinia, A., Vaezi, F. and Nabizadeh, R. 2007. Application of photocatalytic process for removal of methyl tert-butyl ether from highly contaminated water. Iranian Journal of Environmental Health Science \& Engineering 4:215-222.

Hao,O.J., Kim, H. and Chaing, P.C. 2000. Decolorization of wastewater. Critical Reviews. Environmental Science and Technology 30: 449-505.

Hunger, K., Gregory, P., Miederer, P., Berneth, H, Heid, C. and Mennicke, W. 2004. Important chemical chromophores of dye classes in industrial dyes: Chemistry, properties, applications. (Ed. K. Hunger), Wiley-VCH Verlag, GmbH \& Co. kGaA, Weinheim, FRG.

Ibhadon, A. O. and Fitzpatrick, P. 2013. Heterogeneous photocatalysis: Recent advances and applications. Catalysts 3:189218.

Kulkarni, M. and Thakur, P. 2014. Photocatalytic degradation and mineralization of reactive textile azo dye using semiconductor metal oxide nanoparticles. International Journal of Engineering Research and General Science 2(2): 245-254.

Kumar, A., Hitkari, G., Singh, S., Gautam, M.and Pandey, G. 2015. Synthesis of Ni$\mathrm{TiO}_{2}$ nanocomposites and photocatalytic degradation of oxalic acid in wastewater. International Journal of Innovative Research in Science, Engineering and Technology 4(12):12722-12731.

Landmann, M., Rauls, E. and Schmidt, W.G. 2012. The electronic structure and optical response of rutile, anatase and brookite $\mathrm{TiO}_{2}$. Journal of Physics: Condensed Matter 24:1- 
6.

Li, Y. and Chen, W. 2011. Photocatalytic degradation of Rhodamine $\mathrm{B}$ using nanocrystalline $\mathrm{TiO}_{2}$-zeolite surface composite catalysts: effects of photocatalytic condition on degradation efficiency. Catalysis Science \& Technology 1:802-809.

Mahadwad, O. K., Parikh, P. A., Jasra, R. V. and Patil, C. 2011. Photocatalytic degradation of reactive black-5 dye using $\mathrm{TiO}_{2}$ impregnated ZSM-5. Bulletin of Materials Science 34: 551-556.

Mann, U.S., Dhingra, A. and Singh, J. 2014. Water pollution: causes, effects and remedies. International Journal of Advanced Technology in Engineering and Science 2: 1-5.

Molea, A. and Popescu, V. 2011. The obtaining of titanium dioxide nanocrystalline powders. Journal of Optoelectronics and Advanced Materials-Rapid Communications5: 242-246.

Munusamy, S., Aparna, R.S. and Prasad, R.G. 2013. Photocatalytic Effect of $\mathrm{TiO}_{2}$ and the effect of Dopants on Degradation of Brilliant green. Sustainable Chemical Processes, 1:4: 1-8.

Nguyen, T. A. and Juang, R. S. 2013. Treatment of waters and waste waters containing sulfur dyes - A review. Chemical Engineering Journal 219: 109-117.

Poyatos, J. M., Munio, M. M., Almecija, M. C., Torres, J. C., Hontoria, E. and Osorio, F. 2010. Advanced oxidation processes for wastewater treatment: State of the art." Water, Air and Soil Pollution 205:187-204.

Rauf, M. A. and Ashraf, S. S. 2009. Fundamental principles and applications of heterogenous photocatalytic degradation of dyes in solution. Chemical Engineering Journal151:10-18.

Tehrani-Bagha, A. R., Mahmoodi, N. M and Menger, F. M. 2010. Degradation of a persistent organic dye from colored textile wastewater by ozonation. Desalination 260 : 34-38.

Wang Q, Liu X, Wei, Dai J. and Li, W. 2015. Ferromagnetic Property of $\mathrm{Co}$ and $\mathrm{Ni}$ Doped $\mathrm{TiO}_{2}$ Nanoparticles. Journal of Nanomaterials 2015:1-5.

Zhang, X. and Liu, Q. 2008. Visible-light-induced degradation of formaldehyde over titania photocatalyst Co-doped with nitrogen and nickel. Applied Surface Science 254: 4780-4785. 